\title{
Fuzzy Decision System for Banking Services
}

\author{
Suvobrata Sarkar
}

\begin{abstract}
The Aim of this paper is to develop a generalized fuzzy decision system for all the customers who have applied for loans from any Banks in India. Before the Sanction or final Approval of the loans, the Bank's Management Authorities need to take into consideration of various factors related to the respective customers like Age, Annual Income, Loan Repay, Monthly Transaction, Account Balance, and Security Deposits. The Bank obtains sufficient details about all the customers who have applied for Loans and the management authorities give their opinion linguistically about the various factors of each customer. Then a decision is taken to find out the most desired customer to avail the Loan. A Requirement Fuzzy Subset has been formulated. A Relationship is formed between the customers applied for loan and Management's opinion using the Fuzzy subset representation. The Index of Fuzziness of various Management Authorities are measured and compared. A decision system has been developed using fuzzy distance Approach to select the most desired customer for availing the Loan.
\end{abstract}

Index Terms-Fuzzy Distance Measures, Fuzzy Hamming Distance, Fuzzy Hurwicz's Decision Set, Loan Evaluator.

\section{INTRODUCTION}

One of the most Prominent concerns being faced by the Banks is to retain the customers. Today, in India apart from public sector banks, there are several private sector Banks who are providing several easy and attractive schemes of loans to the customers at competitive Interest rates. Moreover, the overall process of sanction of loans usually takes within 7-8 days. Online Banking services deliver a new level of control, simplicity and efficiency to the way the customers and bank, invest and communicate.

But getting the most out of the services the customers requires learning and practice. High cost of customer Acquisition and customer education requires companies to make large upfront investments on customers. However, due to easy access to information and wide range of offerings, it is easier for the customers to switch between service providers [1]. The various factors that the Bank considers for each customer who have applied for loans are Age, Annual Income, Loan Repay, Monthly Transaction, Account Balance and Security Deposits.

Fuzzy Decision making system attempts to deal with the vagueness and non-specificity inherent in human formulation of preferences, constraints and goals. Certainty and precision have much too often become an absolute standard in decision-making problems. The excess of precision and certainty in engineering and scientific research and development is often providing unrealizable solutions. Fuzzy logic, based on the notion of relative graded membership, can

The Author is currently with Dr. B.C Roy Engineering College, Durgapur, West Bengal, India as Sr. Lecturer of Computer Science \& Engineering, Department. Ph.:+919434648373. deal with information arising from computational perception and cognition that is uncertain, imprecise, vague, partially true, or without sharp boundaries. Fuzzy logic allows for the inclusion of vague human assessments in computing problems. Also, it provides an effective means for conflict resolution of multiple criteria and better assessment of options. When Management must select among alternatives elements within a database for decision-making purposes, some means for evaluating alternatives record formats representing combinations of data elements is required. A decision problem is deterministic if the management objectives and the data elements are precisely known. If they are not known precisely, it is very difficult to distinguish the relative importance of different data elements. Fuzzy decision making approach can be effectively utilized to tackle such problem of where the information have not been stated precisely.

Table1. Prescribed Requirements for Availing Loan

\begin{tabular}{|l|l|}
\hline Loan Factors & Fuzzy values \\
\hline 1.Age & Young \\
2.Annual income & High \\
3.Loan Repay & Good \\
4.Monthly \\
Transaction \\
5.Account & Frequent \\
Balance & Sufficient \\
6.Security & High \\
Deposits & \\
\hline
\end{tabular}

\section{LOAN EVALUATOR [6]}

The various factors the Bank considers of each customer for Loan Evaluator are Age, Annual Income, Loan Repay, Monthly Transaction, Account Balance, and Security Deposits. Age is obviously a key factor for each customer because the bank usually prefers young -aged persons. The sanction of Loan amount depends solely on the Annual Income of the respective customers. Before providing the loan to the customers the bank must consider whether the customer availing the loan will able to repay the loan amount on time. Usually the customers who applies for loans from the banks falls into one of the four classes -Very good (repay the loan on specified time), Good (repay the loan on time), Ugly (repay the loan late), Bad (does not repay the loan).The bank, of course, wants all its customers to be good. In order to 
maximize the chance that all its customers are good, the bank normally screens each customer for their potential to repay the loan. Each customer is expected to fill detailed forms about themselves, their family, their existing property and occupation. Sometimes, the Banks provides Cash back reward to the customers for their timely repayment of EMI's of their Captioned loan during a specific period of time. Similarly other vital factors which are taken into account by the bank are Monthly Transaction, Account Balance and Security Deposits. Then, the bank recommends the basic requirements of all factors that are taken into consideration for acceptance of Loans which are shown in Table1.

The following Fuzzy terms have been considered for Age:
1) Old
2) Middle-Aged
3) Young
4) Very

Young

The following Linguistic terms have been considered for Annual Income:
1) High
2) Average
3) Low
4) Poor

For Loan Repay:
1) Very Good
2) Good
3) Ugly
4) $\mathrm{Bad}$

For Monthly Transaction:
1) Very Frequent
2) Frequent
3) Average 4) Less

Frequent

For Account Balance:

1) More than Sufficient 2) Sufficient

3) Less than Sufficient 4) Insufficient

For Security Deposits:
1) High
2) Average
3) Low
4) Poor

Fuzzy subset Representation for the Prescribed Requirements Factors of the customers:

Age: $1 / 0.2+2 / 0.8+3 / 1.0+4 / 0.6$

Annual Income: $1 / 1.0+2 / 0.6+3 / 0.4+4 / 0.2$

Loan Repay: $1 / 1.0+2 / 1.0+3 / 0.2+4 / 0.0$

Monthly Transaction: $1 / 1.0+2 / 1.0+3 / 0.6$

$+4 / 0.2$

Account Balance: $1 / 1.0+2 / 1.0+3 / 0.4+4 / 0.2$

Security Deposits: $1 / 1.0+2 / 0.6+3 / 0.4$

$+4 / 0.2$

The Fuzzy subset representation for the various deciding Factors:

Age:

(1) Old : $1 / 1.0+2 / 0.6+3 / 0.4+4 / 0.2$

(2) Middle-Aged : $1 / 0.8+2 / 1.0+3 / 0.6$ $+4 / 0.4$

(3) Young : $1 / 0.2+2 / 0.6+3 / 1.0+4 / 0.8$

(4) Very Young : $1 / 0.2+2 / 0.4+3 / 0.6$ $+4 / 1.0$

Annual Income \& Security Deposits:

[1] High : $1 / 1.0+2 / 0.6+3 / 0.2+4 / 0.0$

[2] Average : $1 / 0.8+2 / 1.0+3 / 0.4+4 / 0.2$

[3] Low : $1 / 0.2+2 / 0.4+3 / 1.0+4 / 0.6$

[4] Poor: $1 / 0.0+2 / 0.2+3 / 0.6+4 / 1.0$

Loan Repay:
(1) Very Good : $1 / 1.0+2 / 0.8+3 / 0.4$ $+4 / 0.2$

(2) Good : $1 / 0.8+2 / 1.0+3 / 0.6+4 / 0.2$

(3) Ugly: $1 / 0.4+2 / 0.6+3 / 1.0+4 / 0.8$

(4) Bad : $1 / 0.0+2 / 0.2+3 / 0.6+4 / 1.0$

Monthly Transaction:

(1) Very Frequent : $1 / 1.0+2 / 0.8+3 / 0.4$ $+4 / 0.2$

(2) Frequent : $1 / 0.8+2 / 1.0+3 / 0.6+4 / 0.2$

(3) Average : $1 / 0.2+2 / 0.4+3 / 1.0+4 / 0.6$

(4) Less Frequent : $1 / 0.2+2 / 0.4+3 / 0.6$ $+4 / 1.0$

Account Balance:

(1) More than Sufficient : $1 / 1.0+2 / 0.8$ $+3 / 0.4+4 / 0.2$

(2) Sufficient : $1 / 0.8+2 / 1.0+3 / 0.6+4 / 0.2$

(3) Less than Sufficient : $1 / 0.2+2 / 0.4$ $+3 / 1.0+4 / 0.6$

(4) Insufficient : $1 / 0.0+2 / 0.2+3 / 0.6$ $+4 / 1.0$

\section{FUZZY DISTANCE MEASURE [4]}

The requirement set of Loan factor for the customers applied for Loan and the management authorities' opinion about each customer have been stated linguistically. The Fuzzy Hamming distance between the prescribed requirement set and the management's opinion set for each customer with respect to each factors has been estimated. Let us consider the case, four customers having their Savings Account in any particular Bank applied for loan in a particular week. The Fuzzy opinion matrix shows the fuzzy opinion about all the four customers applied for loan in view of four management authorities with respect to the loan factor Monthly Transaction has been described below:

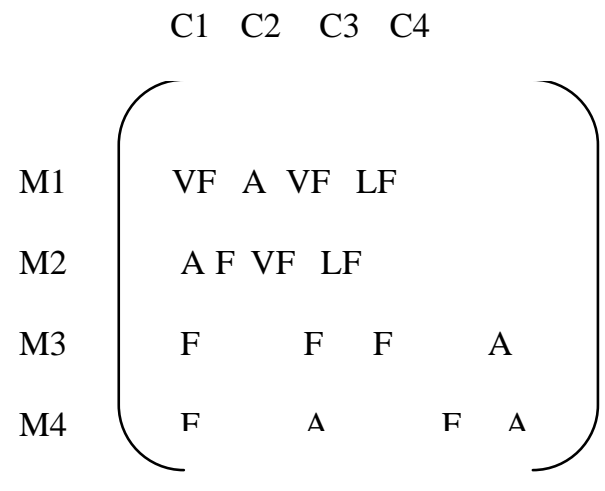

Fig 1. Fuzzy Opinion Matrix

Where the symbol stands for:

VF - Very Frequent, F - Frequent, A - Average, LF - Less Frequent

And

M1, M2, M3, M4 are the management authorities' opinion to the respective customers $\mathrm{C} 1, \mathrm{C} 2, \mathrm{C} 3, \mathrm{C} 4$ applied for Loan to the Bank. 
The Fuzzy subset representation of these Linguistic terms has already been stated. The overall opinion about each customer can be obtained by taking the intersection between the management's opinions for that particular customer. The overall opinion of management with respect to loan factor Monthly Transaction is as follows:

$$
\begin{aligned}
& \mathrm{C}_{\mathrm{O} 1}=1 / 0.2+2 / 0.4+3 / 0.4+4 / 0.2 \\
& \mathrm{C}_{\mathrm{O} 2}=1 / 0.2+2 / 0.4+3 / 0.6+4 / 0.2 \\
& \mathrm{C}_{\mathrm{O} 3}=1 / 0.8+2 / 0.8+3 / 0.4+4 / 0.2 \\
& \mathrm{C}_{\mathrm{O} 4}=1 / 0.2+2 / 0.4+3 / 0.6+4 / 0.6
\end{aligned}
$$

The Fuzzy Decision set regarding Monthly Transaction is obtained by using Hurwicz rule [7],

$$
\mathrm{C}_{\mathrm{OHur}}=\alpha \mathrm{C}_{\mathrm{Hi}}+(1-\alpha) \mathrm{C}_{\mathrm{Li}}
$$

Where $\mathrm{C}_{\mathrm{Hi}}$ are the highest grade $\& \mathrm{C}_{\mathrm{Li}}$ are the lowest grade for all the respective customers applied for Loan and $\alpha$ is the optimism-pessimism index and here we have taken $\alpha=0.8$.

$$
\begin{aligned}
& \mathrm{C}_{\mathrm{Hi}}=1 / 0.8+2 / 0.8+3 / 0.6+4 / 0.6 \\
& \mathrm{C}_{\mathrm{Li}}=1 / 0.2+2 / 0.4+3 / 0.4+4 / 0.2
\end{aligned}
$$

Applying the values of $\mathrm{C}_{\mathrm{Hi}} \& \mathrm{C}_{\mathrm{Li}}$ in the above stated Equation, we get,

$$
\mathrm{F}_{\mathrm{MT}}=1 / 0.68+2 / 0.72+3 / 0.56+4 / 0.52
$$

The prescribed Loan Factor for the Monthly Transaction:

$$
\mathrm{R}=1 / 1.0+2 / 1.0+3 / 0.6+4 / 0.2
$$

The Fuzzy Hamming Distance [5] between the above two sets is given by:

$$
\lambda\left(\mathrm{F}_{\mathrm{MT}}, \mathrm{R}\right)=\sum_{\mathrm{i}=\mathbf{1}}^{\mathbf{4}}\left|\mu_{\mathrm{MT}}\left(\mathrm{x}_{\mathrm{i}}\right)-\mu_{\mathrm{R}}\left(\mathrm{x}_{\mathrm{i}}\right)\right|=0.96
$$

If the Fuzzy opinion set is as close as to the prescribed requirement set, the Hamming distance will be very less.

Similarly, the Hurwicz decision set based on:

Age:

$\mathrm{F}_{\mathrm{A}}=1 / 0.68+2 / 0.56+3 / 0.56+4 / 0.68$

$\lambda\left(\mathrm{F}_{\mathrm{A}}, \mathrm{R}\right)=1.24$

Annual Income \& Security Deposits:

$\mathrm{F}_{\mathrm{AS}}=1 / 0.64+2 / 0.52+3 / 0.52+4 / 0.48$

$\lambda\left(\mathrm{F}_{\mathrm{AS}}, \mathrm{R}\right)=0.84$

Loan Repay:

$F_{L R}=1 / 0.64+2 / 0.68+3 / 0.56+4 / 0.68$

$\lambda\left(\mathrm{F}_{\mathrm{LR}}, \mathrm{R}\right)=1.72$

Account Balance:

$$
\begin{aligned}
& \mathrm{F}_{\mathrm{AB}}=1 / 0.64+2 / 0.68+3 / 0.56+4 / 0.52 \\
& \lambda\left(\mathrm{F}_{\mathrm{AB}}, \mathrm{R}\right)=1.16
\end{aligned}
$$

follows:

The overall fuzzy decision set has been estimated as

$$
\begin{aligned}
\mathrm{F} & =v\left(\mathrm{~F}_{\mathrm{MT}}, \mathrm{F}_{\mathrm{A}}, \mathrm{F}_{\mathrm{AS}}, \mathrm{F}_{\mathrm{LR}}, \mathrm{F}_{\mathrm{AB}}\right) \\
& =1 / 0.68+2 / 0.72+3 / 0.56+4 / 0.68
\end{aligned}
$$

From the above decision set, Customer $\mathrm{C} 2$ has the highest grade of membership. It is observed that Customer $\mathrm{C} 2$ has exactly fit into the prescribed requirement set for availing the loan as recommended by the Bank and hence may be selected as the most desired customer for availing the Loan.

The Index of Fuzziness can be defined with respect to the relative Hamming distance is defined as:

$$
\text { Index of Fuzziness, } \gamma=2.0 / \mathrm{n} * \Delta\left(\mathrm{F}_{\mathrm{MT}}, \mathrm{O}_{1}\right)
$$

Where

$\mathrm{O}_{1} \equiv$ Ordinary subset nearest to fuzzy subset $\mathrm{F}_{\mathrm{MT}}$

$\mathrm{n} \equiv$ Total number of elements contained in fuzzy Hurwicz opinion set

The membership function for the ordinary subset is defined by

$$
\begin{array}{ll}
\beta_{\mathrm{O} 1}\left(\mathrm{x}_{\mathrm{i}}\right)=0 & \text { if } \quad \beta_{\mathrm{MT}}\left(\mathrm{x}_{\mathrm{i}}\right) \leq 0.5 \\
\beta_{\mathrm{O} 1}\left(\mathrm{x}_{\mathrm{i}}\right)=1 & \text { if } \quad \beta_{\mathrm{MT}}\left(\mathrm{x}_{\mathrm{i}}\right)>0.5
\end{array}
$$

Hence the ordinary subset for fuzzy Hurwicz opinion set with respect to Monthly Transaction is given as:

$$
\mathrm{O}_{1}=\left[\begin{array}{llll}
1 & 1 & 0 & 1
\end{array}\right]
$$

The Index of Fuzziness,

$$
\begin{aligned}
\gamma & =2.0 / 4.0 *[0.32+0.28+0.56+0.32] \\
& =0.74
\end{aligned}
$$

Similarly, the indices of fuzziness have been estimated for the overall opinion of the Management authorities with respect to the various Loan factors and found to be approximately equal to 0.7

\section{CONCLUSION}

A Technique for Loan Evaluator of any Bank in fuzzy environment has been presented in this paper. The various Loan factor and the management's opinion about the respective Customers applied for Loan are considered as fuzzy variables. A fuzzy decision set has been formulated which indicates the relative merits of all customers from which a customer with highest grade of merit has been selected. Hurwicz rule has been adopted to derive the fuzzy decision set. Subsequently, when new customers apply for loans, their various loan factors can be verified to check whether the customer is eligible for availing the loan from the bank. Studies reveal that retaining a customer is one of the prime challenges the financial institutions are facing 
worldwide.

\section{REFERENCES}

[1] Vikram Pudi \& P.Radha Krishna, "Data Mining", Oxford University Press, India, 2009, pp. 317-319.

[2] George J.Klir \& Bo Yuan, "Fuzzy Sets and Fuzzy Logic: Theory and Applications", PHI, India, 1995, pp. 390-391.

[3] Fakhreddine O. Karray \& Clarence De Silva, "Soft Computing and Intelligent Systems Design", Pearson Education, India, 2009, pp. $126-128$.

[4] C.W. Chong, V.Ramachandran \& C.Eswaran, " Path Optimization Using Fuzzy Distance Approach", IEEE International Fuzzy Systems Conference Proceedings, Seoul, Korea, 1999.

[5] A.Hauffman, "Theory of Fuzzy Sets", Volume 1, Academic Press, New York, 1975

[6] V.Ramachandran, N.P.Padhy \& S.R .Paranjothi, "Fuzzy Decision System for Recruiting Candidates", National Conferences in Industrial and Applied Mathematics, India, 1994.

[7] V. Ramachandran \& V. Sankaranarayan, "Fuzzy Concepts applied to Statistical Decision Making Methods", 15th IFIP International Conference, Zurich, Switzerland, 1991.

[8] S.R Sudharsanan, "Fuzzy Distance Approach to Routing Algorithms for optimal web path estimation", IEEE International Fuzzy Systems Conference, Singapore, 2001

[9] Zadeh, L. A., "Fuzzy Sets and Systems.", In: Fox, J., ed., System Theory. Polytechnic press, Brooklyn, New York, pp.29-37.

[10] L.A. Zadeh, " The Linguistic Approach and its application to decision Analysis." In: Ho, Y.C and S.K. Mitter, eds., Directions in Large Scale Systems., Plenum Press, New York, pp.339-370.

[11] Zadeh, L. A., "A Theory of approximate reasoning", Machine Intelligence, J.E. Hayes, D.Michie, and L.I. Mikulich (eds.), Vol. 9, Elsevier, New York, 1979, pp.149-194.

[12] Zadeh, L. A., "Fuzzy Sets as a basis for theory of possibility", Fuzzy Sets and Systems, vol.1, Academic Press, Boston, 1978, pp.3-28.

[13] Amit Konar, "Computational Intelligence: Principles, Techniques and Applications", Springer, New York, 2005, pp.37-65.

[14] Amit Konar, "Artificial Intelligence and Soft Computing: Behavioral and Cognitive Modeling of the Human Brain", CRC Press, New York, 2000, pp.284-322.

[15] J.-S.R Jang, C.-T.Sun \& E.Mizutani, "Neuro-Fuzzy and Soft Computing", PHI, India, 2005, pp. 47-64.

[16] Klir, G.J., and Folger, T.A. "Fuzzy Sets, Uncertainty, and Information", Prentice Hall, Englewood Cliffs, New Jersey, 1988.

[17] Dubois, D., and Prade, H. "Fuzzy Sets and Systems", Academic Press, Orlando, 1980.

[18] De Silva, C.W., and Lee, T.H. "Fuzzy Logic in process control", Measurement and Control, vol. 28, CRC Press, Boca Raton, FL, 1994, pp. 114-124.

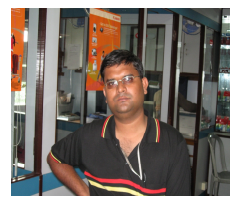

Suvobrata Sarkar received his B.E (CSE) and M.Tech (CSE) in 2003 and 2006 respectively. Currently, he is with Dr. B.C Roy Engineering College as Sr. Lecturer of Computer Science \&Engineering Department, Durgapur West Bengal, India. $\mathrm{He}$ is the member of International Rough Set Society. His Research Interests are in the areas of Fuzzy Sets, Rough Sets, Data Mining and Granular Computing. Recently, he has one International Journal Publication on Fuzzy Sets \& Systems. 